\title{
Viewing the Evolution of Zhou Cang's Image from the Relationship between Pictures and Texts in Printmaking
}

\author{
Siqin Tan \\ Shanghai Publishing and Printing College, Shanghai, China \\ Email: 174596142@qq.com
}

How to cite this paper: Tan, S. Q. (2021). Viewing the Evolution of Zhou Cang's Image from the Relationship between Pictures and Texts in Printmaking. Art and Design Review, 9, 316-321.

https://doi.org/10.4236/adr.2021.94027

Received: September 17, 2021

Accepted: November 12, 2021

Published: November 15, 2021

Copyright ( 2021 by author(s) and Scientific Research Publishing Inc. This work is licensed under the Creative Commons Attribution International License (CC BY 4.0).

http://creativecommons.org/licenses/by/4.0/

\section{(c) (i) Open Access}

\begin{abstract}
Zhou Cang is a well-known character in the novel "The Romance of the Three Kingdoms". How his image of the mighty man came into being in the scroll paintings and the illustrations in the novels of the Romance of The Three Kingdoms in Ming and Qing Dynasties, and mainly folklore scholars discussed it from the literature and folklore legend. This article starts from the perspective of the illustrations in the novel "Romance of the Three Kingdoms" in the Ming and Qing Dynasties, and compares the content of the novels. It is found that the image of Zhou Cang has gone through the three phases of the Jin and Yuan Dynasties irregular period, the basic stereotype period in the Ming Dynasty, and the popular period in the Qing Dynasty.
\end{abstract}

\section{Keywords}

Romance of the Three Kingdoms, Zhou Cang, Guan Yu, Graphical Relationship, Novel Prints

\section{Introduction}

Zhou Cang is a well-known character in "The Romance of the Three Kingdoms". In Ming and Qing art works, he usually appears as the image of a big man with a beard and an angry face. The archetype of "The Romance of the Three Kingdoms", does not appear in the original text of "The Romance of the Three Kingdoms", where Zhou Cang's popular image of a great man has become a question. The academic circle has not paid much attention to this, and as a character in the novel, the illustrations are a more appropriate entry point. Therefore, this article attempts to explore the evolution of Zhou Cang's images from the perspective of corresponding images and texts in Ming and Qing prints. 


\section{Early "Zhou Cang” Image}

Zhou Cang almost always appears with Guan Yu in literary works, so if you want to explore the source of Zhou Cang's image, you need to start with Guan Yu's image. Blackwater unearthed in the city, now in the possession of St. Unearthed in the city of Heishui, the Jin Dynasty print "The Statue of King Wu'an" from the Saint Parkersburg branch of the Institute of Oriental Studies of the Russian Academy of Sciences is an earlier surviving image of Guan $\mathrm{Yu}$, this figure painted five tufts of beard Guan Yu sitting under pine trees, surrounded by five Famous soldiers, one person holding a shield, one person holding a flag, one person wearing armor, one person holding a Guanzi banner, one person holding a sword, although there is a genus holding a big sword behind him, from the perspective of positional relationship, appearance characteristics, etc., this person is not outstanding compared with the rest of the genus with flags and short knives.

In the illustrated prints of the "Guan Gong Single Sword Association" section of the "Zhizhi New Journal Quanxiang Pinghua" (Anonym, 1321-1325) in the Yuan Dynasty, there is an image of a strong bruised man holding a big knife following Guan Yu. On the right side of this print, there are five sergeants playing music at the banquet. In the middle, Guan Yu grasps Lu Su with one hand and swings a fist with the other. It is very consistent with the characteristics of Zhou Cang in the later period. "Guan Gong Single Sword Association" corresponds to the text "On the day of Guan Gong light bow and short arrow, there are no more than 50 people who are acquainted with horses and swords, and went south to Lu Su Village... Three times in a row, Guan Gong was furious and stopped Lu Su. Guan Gong said that the thieves will have nothing to do with banquets. The name is Single Sword Club, so that the soldiers will not sing music and Er Yan Yu will not sing. Don't dare, Guan Gong will spare his life and go back to Jingzhou". It can be seen that there is no special mention of the name of his entourage, but only "more than fifty people". In addition, the text also clearly mentions that Guan Gong only brought short swords and light bows to the banquet. The waist hangs a single sword, but in the illustration, there is a general holding a big knife. It can be seen that the illustration here does not completely correspond to the text of the novel. In addition, the image of the horse and the knife following Guan $\mathrm{Yu}$ is not fixed. In the remaining illustrations, Guan Yu usually appears as a single horseman, but there is only one example.

Not only that, but Zhou Cang's name also appeared in "Zhizhi New Journal Quanxiang Pinghua Three Kingdoms", but at this time there was no relationship between Zhou Cang and Guan Yu. He appeared after Guan Yu's death, and Zhuge Liang left Qishan for the fifth time. A "Han General" appeared on the stage, and Sima Yi, who came to steal the Wooden Cow Flowing Horse Scripture, was humiliated by Zhuge Liang's order, but the engraving illustrations did not depict this. It can be seen that although "The Romance of the Three Kingdoms" has not yet been published, the name of Zhou Cang has been mentioned 
in the Yuan Dynasty, Lu Zhen's book "Tongshan Lao Nong Ji" (Lu, 1790) in the Yuan Dynasty contains an article "Wu'an Wang Temple Ji", which mentions "Lampei Xiaxi Guiqi" Yang, take the red rabbit and come from Zhou Cang, confirms Zhou Cang's identity as a follower of Guan Yu in the text, but has not yet clearly matched Zhou Cang with the image of the later bearded man with a sword.

\section{Out between the Three Countries on Behalf of Graphic Novels Zhou Cang Image}

All this in the early Ming Dynasty, "Three Kingdoms" continue to print and publish that in Speaking of the number of events that Zhou Cang, are summarized as follows: 1) "Kung thunders cut Cai Yang" in the first stage, "the new version has a Woniushan, there is a mountain Kansai, surnamed Zhou name warehouse, arms have power extremely heavy, plate rib Qiu beard, describe are great", Zhou Cang professed to admire Guan Yu for a long time, so he followed. This is one of the few descriptions of Zhou Cang's image in the book; 2) "Liu Xuande defeated and left Jingzhou" Zhou Cang followed Guan Yu and Guan Ping led his army to retreat Zhang Yun; 3) "Zhou Gongjin Chibi fight hard" in the follow Guan Yu Guan Ping ambush Cao Cao go Huarong; 4) "Yan Yan Zhang Feiyi release" Guan Yu stationed in Jingzhou; 5) "Kuan solo run" led a number of Kansai Han follow Guan Yu went to insurance; 6) When "Kuan Shuiyanqijun" because of the good water and captured Pound; 7) "Yuquan Shan Guan Gong was a saint", Zhou Cang committing suicide, and Guan Yu Guan Ping with Vision Yuquan Hill.

"Popular Romance of the Three Kingdoms" (Luo, 1591) in the $19^{\text {th }}$ year of Wanli illustration Zhou Cang appears to refer the text Zhou Cang the chapter edition after finishing painted illustrations can be found, "thunders cut Cai Yang Kung" only draw Guan Cai Yang cut the scene from his horse, Liu Xuan defeated "Walking Jingzhou" behind the mountain, painted Guan $\mathrm{Yu}$ and a general with a long spear, but I don't know whether it was Zhou Cang or Zhang Fei. In "Cao Cao's defeat on Huarong Road" and "Guan Yun Changyi Shi Cao Cao" Guan Yu was accompanied by a Qingqi-bearded warrior, but the two beards of the characters are different. In the "Guan Yun Chang's Single Swordsman's Meeting", the bearded man at the bow station is holding the sword in his hand. It should be Zhou Cang. In "Guan Gong Xian Sheng", the one who followed Guan Yu to hold the banner should be Zhou Cang. In addition, in "Guan Yun Long Scrape the Bone Healing Poison", there was a big man with a beard holding a Guan knife standing aside watching Guan Gong play chess.

In Wanli's 33rd Year of “Three Kingdoms” (Luo, 1605) and Wanl's 38th year of "Three Kingdoms" (Luo, 1610), Zhou Cang only appeared in the two illustrations of "Zhou Cang Kneeling and Meeting Guan Yu" and "Yu Ji's Second Wife Takes Zhou Cang", with facial expressing the beard, the rest such as "Guan Yun Chang Niu Su boarding and leaving", "Pu Jing recruits an Yun Chang Hades" 
and so on, are without Zhou Cang.

It can be seen that Zhou Cang in the engraving illustrations is the same as the description in the text. It usually appears with Guan Yu, but does not appear much in the illustrations in the novel, and despite the fact that the book has a strong description of Zhou Cang, "appearance of clear description, illustration and not a same, especially the beard part, the after image comparison can be found, Wanli nineteen years", popular Romance of the Three Kingdoms in Zhou Cang image can be divided into two types, one is a full beard, the other is that only the lower jaw has a beard. It can be seen that the image of Zhou Cang in the description of the novel has been fixed, and the corresponding engraving illustrations did not follow.

\section{The Establishment of the Image of Zhou Cang in the Qing Dynasty-Taking "Pictures and Records of the Holy Relics of Emperor Guan Sheng" as an Example}

By the Qing Dynasty, the image of Zhoucang gradually became complete. The Collection of Lu Zhan during the Qianlong Period, and the updated "Pictures of Guan Shengdijun Sacred Relics" (Lu, 1769) by Yu Chenglong, Chen Hongmou, and Shen Deqian. More than fifty prints of Guan Yu's life stories were drawn, all with text explanations, of which a single version of Zhou Cangli was drawn. At the end of Juan Yi Ren Department, Zhou Cang is strong in body, with a curly beard on his face, wearing armor, head and hat, and Guan Yu's sword is inserted behind him. There is the text Jiang Zhou, the general name warehouse, living in Wo Niu Mountain, brave and brave, five years in Jian'an. When encountering the emperor, Gai Suyang's loyalty and righteousness, he returned, serving day and night, with two hearts, followed the emperor for twenty years as a day, and could not escape the difficulties and dangers, went to the water to capture Pound alive, and lonely defend Maicheng. "When Emperor Guan was in trouble, he and Wang Fu joined the army", he gave a detailed account of Zhou Cang's life. Zhou Cang's appearance is very stable in the "Guan Sheng Emperor Sacred Relics". The appearance and clothing features of Zhou Cang in scenes such as "Supervisor Jingzhou" and "Single-handedly Going to the Meeting" are basically the same as here, and are also common in the art of Qing Dynasty. The image is basically the same.

In addition, it is also worth noting that in the "Guan Sheng Emperor Sacred Relics" “Jiang Meng Zhou Shou”, a Qing dynasty official is napping in the Cao $\mathrm{Lu}$, dreaming that Guan Yu and Zhou Cang are coming by the clouds, and the text says "Jie Liang" The prince of the prefect Jinshan prince was named Zhu Dan. When he was not in the office, he traveled to Suzhuo in Ding Youqiu. The Emperor Meng Yingying said that he said that the troubled rafters wrote about his life, and the general of Gu Zhou said that he was very drunk and needed help. To hurt, the next day I met a guest invited to drunk and fall off the horse, touched the huge boulder without any harm, until Wuwu, he kept and reunited 
with the strange bricks of the well-told by the people, the emperor said before, and he almost wanted to show his first tomb cloud. In the legend of the sacred relic story arranged by later generations, Zhou Cang already occupies an important seat.

The establishment of the image of Zhou Cang in the Qing Dynasty is probably related to the prevalence of Guan Yu's belief in the Qing Dynasty. After being named by Emperor Xianzong of the Ming Dynasty and Shenzong successively as "Zhuangmiaoyi, brave, Wuanxianling Yingji Wang" and "Guansheng the Great", Shunzhi dubbed Guan Yu as the "Loyalty Shenwuguan Shengdi", and Qianlong named him the "Loyalty God Wulingyouguan" "Holy Emperor", Daoguang also named him as "the loyal god of martial arts, the spirit of the god of loyalty and bravery, and the prestige of the emperor Guan Sheng", the Qing Dynasty official folk built many temples for worship. In Qian Zeng's "Reading Min Qiu Ji” (Qian, 1726) in the Early Qing Dynasty, there was an article "Re-editing the Second Volume of the Collection of Yi Yong Wu An Wang". It was mentioned that "the statue of Zhou Cang was built on the right of the god seat in Guan Yu Temple. It has been passed for a long time. People can only be seen in the legends of novels. How can they be used as evidence Zhou Cang is beside Guan Yu? It can be seen that in the Guan Yu sacrifice at that time, the statue of Zhou Cang had been standing by the side as Guan Yu's entourage, and it "has been passed for a long time". In addition, Liang Zhangju's "Ying Liao Cong Hua" (Liang, 1935) in the mid-Qing Dynasty It is mentioned that there are many related temples in the mountain villages in the hometown. "Every few miles must be related to the temple. There must be many statues in the temple, and there must be a statue of General Zhou next to it, which is known as Zhou Cang". Not only that, but the people will also worship Zhou Cang separately. General Zhou's shrine is supernatural, and the chatter in the temple is contemptuous.

There is a "black prostitute" in the "Jian $\mathrm{Hu}$ Ji" (Chu, 2012) written by Chu Renhuo in the Qing Dynasty, which mentioned that "the famous prostitute Li San in the late Ming Dynasty was good at fame and poetry, and the color was very dark. Shanyi Guangling Fu Jia also wrote in black. Guo Wan called Huang Yinger mocked and said, Ink Li Sanniang, Hei Xuanfeng brothers and sisters, Zhang Fei used to go around with the mandarin account, go around the overlord, and then take Zhou Cang, Zhong Kui was also in front of the door, Yuchi helped General Wen to sell well and hook up Stove King". It can be seen that the image of Zhou Cang at this time is similar to that of Li Kui, Zhang Fei, Xiang $\mathrm{Yu}$, Zhong Kui and others. The black-faced and bearded man is deeply rooted in the people.

The "prototype" of the Three Kingdoms Zhoucang of the Three Kingdoms There are no characters in the original text. The popular image of Han Zhoucang is problematic. There is not much attention from academia. The characters and illustrations in the novels and the prints of the novel are more suitable to entry points. Therefore, this article attempts to explore the evolution of Zhou Cang's 
image from the perspective of corresponding images and texts in Ming and Qing prints.

\section{Conflicts of Interest}

The author declares no conflicts of interest regarding the publication of this paper.

\section{References}

Anonym (1321-1325). Records of Three Kingdoms. Shanghai Ancient Books Publishing House.

Chu, R. H. (2012). Jianhu Collection. Shanghai Ancient Books Publishing House.

Liang, Z. J. (1935). Couplets. China Commercial Press.

Lu, Z. (1790). Tongshan Old Farmers. The Four Library of Qingyuan Pavilion.

Lu, Z., Yu, C. L., Chen, Z. M., \& Shen, D. Q. (1769). The Records of Guan Records (Dun Wu Tang Version). China Publishing House.

Luo, G. Z. (1591). The Popular Romance of the Three Kingdoms. Shanghai Ancient Books Publishing House.

Luo, G. Z. (1605). Biography of the Three Kingdoms. Shanghai Ancient Books Publishing House.

Luo, G. Z. (1610). The Biography of the Three Kingdoms. Shanghai Ancient Books Publishing House.

Qian, Z. (1726). Reading Min Qiu Ji. Cultural Relics Publishing House. 